\title{
FORMATION AND NORMALIZATION OF LEGAL TERMINOLOGY IN THE FIELD OF DIGITAL TECHNOLOGIES ${ }^{1}$
}

\author{
Marina L. Davydova \\ Volgograd State University, Volgograd, Russia
}

\begin{abstract}
Based on the latest legal texts, the article examines the process of forming the terminology of legal acts used in the digital technology field. The empirical base of the study consists of two blocks of legal texts: acts of strategic planning (strategies, national programs, passports of federal projects, etc.) and regulatory legal acts (federal laws and their projects) published in the period from 2016 to 2019. The peculiarities of lexical representation of the first group of documents (unsystematic use of terms, the use of metaphors and many words in quotation marks, excessive definitions and explanations, erosion of terminological apparatus of jurisprudence) indicate, in the author's opinion, two main features of the language of programmatic and strategic documents related to the field of digital technologies: 1) the declarative nature of the text, a large number of journalistic expressions have an emotional rather than rational effect; 2) there is no established scientific terminology and professional language which one can use in order to speak about digital legal relations. The second group of texts is now small in number but allows us to conclude that a much more careful approach to the terminological apparatus is taken. In general, the process of forming a legal terminological system in the field of digital technologies goes through several stages: the formation of the terminology of information technology field (largely due to borrowings from the English language); the inclusion of term-like units in the language of programmatic and strategic documents; development of legal terms proper, enshrined in the texts of regulatory legal acts.

Key words: term, terminology, legal term, language of law, terminological system of law, digital technologies, digital economy.

Citation. Davydova M.L. Formation and Normalization of Legal Terminology in the Field of Digital Technologies. Vestnik Volgogradskogo gosudarstvennogo universiteta. Seriya 2. Yazykoznanie [Science Journal of Volgograd State University. Linguistics], 2020, vol. 19, no. 4, pp. 52-63. (in Russian). DOI: https://doi.org/ 10.15688/jvolsu2.2020.4.5
\end{abstract}

УДК 81’373.46:340.113

Дата поступления статьи: 16.01.2020

ББК 81.053 .2

Дата принятия статьи: 11.05.2020

\section{ФОРМИРОВАНИЕ И НОРМАЛИЗАЦИЯ ЮРИДИЧЕСКОЙ ТЕРМИНОЛОГИИ В СФЕРЕ ЦИФРОВЫХ ТЕХНОЛОГИЙ ${ }^{1}$}

\author{
Марина Леонидовна Давыдова \\ Волгоградский государственный университет, г. Волгоград, Россия
}

\begin{abstract}
Аннотация. В статье на материале новейших юридических текстов исследуется процесс упорядочения юридической терминологии в документах, функционирующих в сфере цифровых технологий. Эмпирическую базу исследования составили юридические тексты двух групп: акты стратегического планирования (стратегии, национальные программы, паспорта федеральных проектов) и нормативно-правовые акты (федеральные законы, их проекты, подзаконные акты), изданные в период с 2016 по 2019 год. Особенности лексического состава документов первой группы (отсутствие системности в закреплении терминов, метафоричность в использовании терминов, употребление множества слов в кавычках, размывание терминологического аппарата юриспруденции, избыточность некоторых определений и пояснений) свидетельствуют о двух основных чертах языка стратегических документов, относящихся к сфере цифровых технологий: 1) декларативность текста, использование большого количества публицистических оборотов, стрем(2) ление компенсировать рациональное воздействие эмоциональным; 2) отсутствие устоявшейся научной
\end{abstract}


терминологии и профессионального языка, на котором можно говорить о цифровых правоотношениях. В результате анализа текстов второй группы выявлено, что их составители более квалифицированно подходят к употреблению терминов сферы цифровых технологий. Показано, что процесс формирования и упорядочения юридической терминологии в области цифровых технологий проходит несколько этапов: становление терминологии информационно-технологической сферы (в значительной мере за счет заимствования слов из английского языка); включение терминоподобных единиц в язык стратегических документов; выработка на их основе собственно юридических терминов, закрепляемых в текстах нормативноправовых актов.

Ключевые слова: термин, терминология, юридический термин, язык права, терминосистема права, цифровые технологии, цифровая экономика.

Цитирование. Давыдова М. Л. Формирование и нормализация юридической терминологии в сфере цифровых технологий // Вестник Волгоградского государственного университета. Серия 2, Языкознание. 2020. - T. 19, № 4. - C. 52-63. - DOI: https://doi.org/10.15688/jvolsu2.2020.4.5

\section{Введение}

Развитие юридического языка обусловлено влиянием множества факторов, в числе которых важное место занимает появление новых сфер правового регулирования и новых правовых институтов. Именно этот процесс происходит сейчас в одной из наиболее активно развивающихся областей человеческой деятельности - в сфере цифровых технологий. Возникновение и развитие новых общественных отношений, требующих правового регулирования, приводит к появлению нормативных текстов, содержащих новую для права терминологию. Специфика формирования и упорядочения такой терминологии и составляет предмет данного исследования.

\section{Материал и методы исследования}

Материалом для исследования выступают тексты двух групп, наиболее активно обогащающие терминосистему права в рассматриваемой сфере и позволяющие оценить ее современное состояние: акты стратегического планирования и нормативно-правовые акты. Это тексты документов, посредством которых лексика соответствующих профессиональных областей (информационных технологий, экономики, менеджмента и др.) попадает в юридический дискурс. Традиционно ключевую роль в процессе юридического терминотворчества играют нормативно-правовые акты (в первую очередь федеральные законы), то есть изданные компетентными органами официальные источники общеобязательных правил поведения. В силу новизны регу- лируемых отношений и длительности законотворческой процедуры, законов, регламентирующих сферу цифровых технологий, принято пока крайне мало. Гораздо более многочисленной является группа правовых текстов программного характера (стратегии, национальные программы, паспорта федеральных проектов и т. п.). Их правовой статус в юридической науке до конца не определен. В частности, дискуссионными остаются вопросы о том, каковы конституционные основы функционирования подобных документов, их соотношение с нормативно-правовыми актами, юридическая сила и положение в иерархии традиционных источников права [Догадайло, 2019, с. 31-35]. Тем не менее такие правовые акты активно используются в практике современного государственного управления. На языковую специфику этих актов уже обращали внимание исследователи (см., например: [Быстрова, 2017; 2018]). Нас данные тексты интересуют в связи с тем, что именно они сейчас представляют собой наиболее активные источники новых слов, претендующих на включение в терминосистему права. Хронологически их создание предшествует созданию законодательных актов, что и определяет последовательность их рассмотрения в настоящей статье.

Методику научного поиска составили: формально-юридический метод, разработанные юриспруденцией приемы и методы толкования права (языковой, логический, систематический, историко-политический), а также лингвистические методы (компонентный, контекстуальный, сопоставительный анализ). 


\section{Результаты и обсуждение}

\section{Акты стратегического планирования и их языковые особенности}

Издание программных документов в настоящее время происходит во множестве сфер правового регулирования, которые государство решает признать приоритетными или значимыми. В частности, в сфере цифровых технологий в течение последних лет приняты: Стратегия научно-технологического развития Российской Федерации (утв. Указом Президента РФ от 01.12.2016 № 642), Стратегия развития информационного общества в Российской Федерации на 2017-2030 гг. (утв. Указом Президента РФ от 09.05.2017 № 203); Программа «Цифровая экономика Российской Федерации» (утв. распоряжением Правительства РФ от 28.07.2017 № 1632-p); Указ Президента РФ от 07.05.2018 № 204 «О национальных целях и стратегических задачах развития Российской Федерации на период до 2024 года»; Паспорт национальной программы «Цифровая экономика Российской Федерации» (утв. Президиумом Совета при Президенте РФ по стратегическому развитию и национальным проектам 24.12.2018); паспорта федеральных проектов «Нормативное регулирование цифровой среды», «Информационная безопасность», «Информационная инфраструктура», «Цифровые технологии», «Кадры для цифровой экономики», «Цифровое государственное управление» (утв. Правительственной комиссией по цифровому развитию, использованию информационных технологий для улучшения качества жизни и условий ведения предпринимательской деятельности 25.12.2018); Национальная стратегия развития искусственного интеллекта на период до 2030 г. (утв. Указом Президента РФ от 10.10.2019 № 490) и др.

С технико-юридической точки зрения многие из перечисленных документов далеки от совершенства. Так, оценивая паспорта федеральных проектов, предусмотренных Национальной программой «Цифровая экономика Российской Федерации», эксперты отмечают отсутствие у них должного официального утверждения (на уровне постановления или распоряжения правительства); несовпадение нумерации в перечнях направлений деятельнос- ти, целей и задач, закрепленных в связанных по смыслу документах; несоответствие или отсутствие явной корреляции целей и показателей их достижения; отсутствие информации об индикаторах, несмотря на активное употребление сочетания показатели и индикаторы и т. п. (Паспорт нацпрограммы). Все это создает общее впечатление некоторой небрежности и поспешности в подготовке данных актов. В целом оно сохраняется и при анализе их терминологической составляющей.

Можно выделить ряд общих черт, характеризующих лексический состав этих правовых актов.

Отсутствие системности в закреплении терминов. Системность как важнейшее свойство документного текста наглядно проявляется в использовании дефиниций [Косова, 2012, с. 7]. В анализируемых актах единый подход к ним отсутствует. В одних документах дается обширный перечень дефиниций, в других - понятия не определяются или определяются контекстуально. Так, в Стратегии развития информационного общества в Российской Федерации на 2017-2030 гг. закреплены 17 дефиниций, в том числе сугубо информационные (индустриальный интернет, облачные вычисления, объекты критической информачионной инфраструктуры, туманные технологии), а также термины более широкого применения, в частности цифрровая экономика. В других документах приведены лишь вспомогательные термины, не связанные с содержанием регулируемых социально-экономических процессов. Например, Положение «О системе управления реализацией национальной программы “Цифровая экономика Российской Федерации”» (утв. Постановлением Правительства РФ от 02.03.2019 № 234) закрепляет дефиниции терминов проект, федеральный проект Программы, региональный проект Программы и др.

Одно из базовых понятий рассматриваемой сферы - «цифровая экономика» - получает свое определение в Стратегии развития информационного общества в Российской Федерации на 2017-2030 гг.: «Цифровая экономика - хозяйственная деятельность, в которой ключевым фактором производства являются данные в цифровом виде, обработка больших объемов и использование результа- 
тов анализа которых по сравнению с традиционными формами хозяйствования позволяют существенно повысить эффективность различных видов производства, технологий, оборудования, хранения, продажи, доставки товаров и услуг». Программа «Цифровая экономика Российской Федерации», принятая спустя 3 месяца после Стратегии, полноценной дефиниции этого ключевого для данной сферы понятия не содержит. Однако вместо того, чтобы отослать к уже существующему определению, авторы Программы в первом ее абзаце частично воспроизводят его в более краткой и декларативной форме, никак не выделяя в тексте. От первоначальной версии оставлена лишь фраза о том, что «данные в цифровой форме являются ключевым фактором производства во всех сферах социально-экономической деятельности», но добавлена следующая характеристика: «что повышает конкурентоспособность страны, качество жизни граждан, обеспечивает экономический рост и национальный суверенитет». Безусловно, перечисленные цели важны для развития государства, но не являются признаками, образующими понятие. Очевидно, что цифровая экономика останется цифровой, даже если не будет направлена на обеспечение национального суверенитета. Таким образом, помимо того, что допускается дублирование дефиниций одного термина в двух правовых актах, вторая версия определения включает больше декларативных компонентов в ущерб содержательным.

В некоторых документах крайне неудачно названы сами понятия. Так, в ст. 4 Стратегии научно-технологического развития Российской Федерации содержатся дефиниции понятий «независимость» и «конкурентноспособность». Если во втором случае по контексту определения еще можно сделать вывод, что речь идет о конкурентноспособности государства («формирование явных по отношению к другим государствам (выделено мною. $-M$. Д.) преимуществ в научно-технологической области...»), то понять, о чьей независимости (государства, российской науки, отдельных ученых) говорится в первой дефиниции, невозможно: «Независимость достижение самостоятельности (чьей? M. Д.) в критически важных сферах жизне- обеспечения за счет высокой результативности исследований и разработок и практического применения полученных результатов». Разумеется, речь здесь идет не об определении понятия «независимость» вообще, а об уточнении его значения для иелей данного правового акта, но даже в этом случае корректнее было бы конкретизировать формулировку и ограничить объем понятия, используя термины независимость / конкурентноспособность государства в научно-технологической сфере.

\section{Метафоричность в использовании} терминов. Авторы исследуемых нормативных текстов вводят в оборот большое количество слов, используемых в переносном значении, придавая им статус терминов: искусственный интеллект, экосистема циифровой экономики, информационное пространство, облачные и туманные вычисления, электронное правительство, электронная демократия, регуляторные песочнииы, экосистема умной городской среды, сквозные ичифровые технологии, ичифровая грамотность, виртуальная лаборатория, дорожная карта и др.

С одной стороны, метафоризация - распространенный способ терминообразования. В процессе терминогенеза мысль часто вынуждена извлекать из общего языкового резервуара уже существующую лексему, которая переносится и метафорически переосмысливается, чтобы обозначить нарождающееся понятие [Assal, 1994, p. 235]. С другой стороны, правоведы, как правило, критически относятся к избытку метафор в юридическом тексте, подчеркивая, что с их помощью не достигаются точность и адекватность научной мысли [Баранов, Власенко, 2019, с. 18; Черданцев, 2012, с. 251].

Квантитативные показатели свидетельствуют, что метафоризация является периферийным способом образования юридических терминов [Гаврилова, 2019, с. 505], хотя количество терминов-метафор может возрастать в связи со «сложными международными тенденциями унификации и гармонизации юридических понятий в подъязыках разных правовых отраслей» [Власенко, 2014, с. 28]. Вероятно, это и отражается в текстах исследуемых документов. 


\section{РАЗВИТИЕ И ФУНКЦИОНИРОВАНИЕ РУССКОГО ЯЗЫКА}

Из трех выделяемых в науке способов образования терминов (построение производных слов, усеченных слов и словосочетаний; использование уже существующих слов путем изменения их значений; заимствование терминов из другого языка [Лотте, 1982, с. 7]) терминологическую метафору исследователи относят ко второму способу терминогенеза [Лыкова, 2016, с. 106]. Особенность терминов-неологизмов цифровой сферы состоит в том, что практически все метафоры заимствованы, преимущественно из английского языка. Умные города (smart cities), облачные технологии (или облачные вычисления, cloud computing), облачные услуги (cloud services), Интернет вещей (Internet of things), nортфель (portfolio) проектов, большие вызовы (grand challenges), регуляторные песочниць (regulatory sandboxes) и т. п. - все эти слова и словосочетания представляют собой калькированный перевод терминов, многие из которых являются элементами складывающейся в настоящее время универсальной (международной) терминологии, хотя, разумеется, далеко не все из многочисленных заимствований вправе претендовать на статус юридического термина.

Употребление множества слов в кавычках. В текстах программных документов широко представлены такие примеры: «умные города», «сквозные технологии», «дорожные картыл, «стартапыл, «облачные» услуги, «облако», «портфели» проектов, «драйвер» (в значении «катализатор», «ускоритель»), «цифровая грамотность», «узкие места», "Интернет вещей», научные установки класса «мегасайенс», "регуляторные nесочницы» и т. п. Этот прием используется даже тогда, когда употребление конкретного слова уже устоялось и является привычным («Интернет», «дорожная карта») или когда осуществляется простое заимствование иностранного термина, без переноса в значении («стартап»).

В тексте кавычки сразу обращают на себя внимание, однако, будучи во многих случаях неуместными, представляют текст в невыгодном свете. Так, рассуждая об употребляемом в паспортах проектов сочетании «методики» определения показателей, эксперты иронично замечают: «Слово “методики" не случайно взято в кавычки - в абсолютном большинстве случаев эти методики сводятся к достаточно примитивным арифметическим вычислениям, основывающимся на статистических данных, получаемых из различных ведомств» (Паспорт нацпрограммы). Возможно, осторожная самокритика и подразумевалась авторами текста, но вряд ли они ставили цель специально привлечь вниманиек непроработанности этого положения документа.

Размывание терминологического апnарата юриспруденции. Если в одних случаях использование образных выражений обусловлено наличием принятых в мировой практике обозначений (облачные технологии) и призвано обеспечить универсальность терминологии, то в целом ряде других случаев статус термина получают слова, совершенно для этого не подходящие. Яркий пример - закрепление в качестве термина слова веха. В Программе «Цифровая экономика Российской Федерации» содержится фраза: «На базе “дорожной карты” будет разработан план мероприятий, содержащий описание мероприятий, необходимых для достижения конкретных “вех” настоящей Программы...» Создается впечатление, что использование слова «вехи» в кавычках должно указывать на то, что автор текста признает некоторую неуместность в официальном тексте данного образного выражения, но использует его, чтобы продолжить метафорический ряд (дорога - дорожная карта - верстовые столбы, вехи). О такой излишней склонности к поэтизации можно было бы забыть, но в Положении «О системе управления реализацией национальной программы “Цифровая экономика Российской Федерации"» (утв. Постановлением Правительства РФ от 02.03.2019 № 234) мы обнаруживаем п. 3 «Термины (!), используемые в настоящем Положении», первым из которых идет следующее определение: «“Веха” - конечный итог реализации одного или нескольких мероприятий федерального проекта Программы, имеющий самостоятельное значение и ожидаемые результаты (эффекты), значимые для государства, бизнеса или общества».

Более детальное изучение вопроса позволяет обнаружить, что слово веха действительно используется в такой сфере, как управление проектами, в качестве аналога английско- 
го milestone (Веха). Отметим, что это слово приводится далеко не во всех глоссариях по управлению проектами, отсутствует оно и в действующих в этой области государственных стандартах [ГОСТ Р 54869-2011; ГОСТ Р ИСО 9000-2015]. Иногда milestone переводится как «контрольное событие» (Глоссарий). Можно подобрать и другие эквиваленты, которые были бы вполне органичны в тексте правового акта: «ключевое событие» (key event), этап, стадия, ступень.

По нашему мнению, слово веха представляет собой профессионализм, который ни стилистически, ни по степени распространенности соответствующего значения в языке, ни функционально не соответствует статусу юридического термина.

Избыточность некоторых определений и пояснений. Адресанты документов стратегического планирования постоянно пытаются уточнить, усилить свою мысль, например упоминая технологические барьеры («узкие места») или многократно уточняя, что понимается под дорожной картой. Так, в Постановлении Правительства Российской Федерации от 18.04.2017 № 317 «О реализации национальной технологической инициативы» словосочетание дорожная карта употребляется 123 раза, из них 56 раз в контексте планы мероприятий («дорожные картыл)). Если существует стилистически нейтральный и общепринятый синоним план мероприятий, то какова необходимость введения термина дорожная карта? Если он уже введен и широко используется в документах органов исполнительной власти, то, возможно, пора перестать ставить его в кавычки и сопровождать пояснениями.

Все перечисленные тенденции позволяют говорить о двух основных чертах языка программных и стратегических документов, относящихся к сфере цифровых технологий:

1. Декларативность текста, использование большого количества публицистических оборотов свидетельствуют о популизме, стремлении сделать текст понятнее, красочнее или нагляднее. Такие приемы, неуместные в официальном документе, могут косвенно указывать на недостаток его содержательной части, попытку компенсировать рациональное воздействие эмоциональным.
2. Отсутствие устоявшейся научной терминологии, фиксирующей наличие правовых отношений в сфере цифровых технологий. В силу объективных причин значительная часть терминологии заимствуется из английского языка. Такие термины часто носят метафорический характер, что дает стимул отечественным правотворцам к изобретению собственных образных терминов, в итоге снижающих авторитет нормативного текста.

\section{Терминология}

\section{нормативно-правовых актов в сфере цифровых технологий}

В соответствии с паспортом национальной программы «Цифровая экономика Российской Федерации» этап «Нормативное регулирование цифровой среды» должен быть реализован в период с 1 ноября 2018 г. по 31 декабря 2021 г., что предполагает принятие значительного количества нормативно-правовых актов, преимущественно федеральных законов. С определенным отставанием от предусмотренного программными документами графика этот процесс происходит в настоящее время. Анализ текстов принятых и проектируемых законов позволяет увидеть, какие из многочисленных использованных в актах стратегического планирования неологизмов будут восприняты законодательством в качестве официально признанных юридических терминов, а какие продолжат существование лишь на уровне разговорного языка юристов и правовой доктрины.

Имеющиеся (пока немногочисленные) примеры свидетельствуют о том, что законодатели гораздо более взвешенно, чем авторы программных документов, подходят к вопросам терминологии.

Так, паспортом национальной программы «Цифровая экономика Российской Федерации» было предусмотрено принятие федерального закона, регулирующего «краудфандинговую деятельность (деятельность по привлечению инвестиций с использованием инвестиционных платформ)». В название и текст соответствующего закона заимствованное и не очень пока распространенное в русском языке слово краудфандинг не вошло (см.: Федеральный закон от 02.08.2019 


\section{РАЗВИТИЕ И ФУНКЦИОНИРОВАНИЕ РУССКОГО ЯЗЫКА}

№ 259-Ф3 «О привлечении инвестиций с использованием инвестиционных платформ и о внесении изменений в отдельные законодательные акты Российской Федерации»).

Предусмотренный программой закон, регулирующий механизмы формирования и использования «облачной» электронной подписи, пока не принят. На данный момент действует Федеральный закон от 06.04.2011 № 63-Ф3 «Об электронной подписи» (ред. от 23.06.2016), однако в Постановлении Правительства РФ от 08.11.2019 № 1427 «О проведении эксперимента по совершенствованию применения технологии электронной подписи» характеристика «облачная» к данному понятию неприменяется.

Отсутствует пока и закон, регулирующий вопросы создания и функционирования особых правовых режимов в условиях цифровой экономики («регуляторных песочниц»), но в подготовленном Минэкономразвития России проекте (проект Федерального закона «Об экспериментальных правовых режимах в сфере цифровых инноваций в Российской Федерации и о внесении изменений в отдельные законодательные акты Российской Федерации», ID проекта 04/13/07-19/00093066, текст по состоянию на 11.07.2019) используется термин экспериментальные правовые режимы в сфере иифровых инноваций. Термин регуляторные песочницы, достаточно распространенный в зарубежной научной литературе [Hallatt, 2016; Jenik, Lauer, 2017; Wechsler, Perlman, Gurung, 2018; Zetzsche et al., 2017], в тексте проекта не упоминается. Как видно, авторы законопроекта не только отказались от заимствованной метафоры, но и заменили признак «особый» на гораздо более конкретную характеристику «экспериментальный», поскольку атрибутив особый указывает лишь на некие отличия от основного правового режима, а прилагательное эксnериментальный - на временный характер устанавливаемого режима, необходимость оценки его эффективности и определение, в зависимости от нее, дальнейшей судьбы предложенного регулирования. Термин эксnериментальный правовой режим можно считать удачным еще и потому, что отсылает к устоявшейся в юридической науке терминологии - к давно известным и основатель- но разработанным понятиям «правовой режим» [Davydova, Makarov, 2020].

Отметим, что после появления официального варианта термина (хотя бы на уровне проекта федерального закона) документы стратегического планирования начинают использовать его, а не предшествовавший ему образный аналог. Так, утвержденная Указом Президента РФ от 10.10.2019 Национальная стратегия развития искусственного интеллекта на период до 2030 года в п. «а» ст. 49 предусматривает «обеспечение благоприятных правовых условий (в том числе посредством создания экспериментального правового режима) для доступа к данным».

Таким образом, можно предположить, что процесс формирования юридических терминов в области цифровых технологий проходит несколько этапов: 1) формирование терминологии информационно-технологической сферы (в значительной мере за счет заимствований из английского языка); 2) включение ее в язык стратегических документов; 3) выработка на их основе собственно юридических терминов, закрепляемых в текстах нормативно-правовых актов.

\section{Термины и нетермины}

\section{в цифровом юридическом дискурсе}

В условиях, когда большинство нормативно-правовых актов, призванных установить правовые основы технологической модернизации, еще не принято, основным источником новых терминов выступают именно программные документы. Как представляется, многие из содержащихся в них слов и выражений не могут с полным основанием квалифицироваться как термины, поскольку они являются терминоподобными лексемами [Косова, 2010]. Современное терминоведение оперирует понятиями «терминоид» (специальная лексическая единица, используемая для номинации недостаточно устоявшихся (формирующихся) и неоднозначно понимаемых понятий) и «предтермин» (специальная номинация, используемая для называния новых сформировавшихся понятий, но не отвечающая требованиям краткости, точности, стилистической нейтральности, предъявляемым к термину) [Гринев-Гриневич, 2008, с. 43-47]. См. приведенные выше примеры. 
Терминоид как единица незавершенного процесса терминологизации [Горохова, 2014, c. 106] имеет место в ситуации, когда слово, претендующее на статус термина, уже существует и используется в языке, но исчерпывающий набор признаков соответствующего понятия еще не уточнен окончательно. По нашему мнению, именно таково положение дел с понятием «цифровая экономика», которое, несмотря на активное употребление в официальных документах, по-разному определяется в некоторых из них и продолжает вызывать дискуссии в научных кругах. Как отмечают специалисты, «детали развития новой цифровой экономики весьма туманны, а ее соотношение с традиционной материалоемкой и трудозатратной экономикой пока до конца не ясно» [Вайпан, 2018, с. 12].

Значительное количество заимствованных образных выражений можно отнести к предтерминам - словам, обозначающим новые понятия, значение которых уже в достаточной степени ясно, но подходящее наименование пока не подобрано. Предтермином по отношению к термину экспериментальный правовой режим выступает сочетание регуляторная песочнииа. Выражения облачные вычисления, умные города, самоисполняемые договоры и др. еще ждут адекватной замены. В подъязыке компьютерных, информационных и телекоммуникационных технологий в некоторых исследованиях относят заимствования из английского языка к числу терминоидов [Зубарев, 2009, c. 115]. Однако применительно к языку права определяющим здесь является не только содержательная характеристика понятия (насколько утвердился в науке состав его признаков - это во многом вопрос для отдельного научного исследования), но и само наименование термина, которое должно соответствовать официально-деловому стилю, быть точным, информативным и органичным в тексте нормативно-правового акта.

В качестве предтерминов могут выступать и профессионализмы [Лейчик, 2009, c. 106], такие как веха проекта. Возможность того, что подходящий официальный аналог не будет найден и эти единицы будут включены в текст закона, существует. Однако полноценными терминами они, вероятнее всего, не ста- нут, а сохранят статус квазитермина (закрепленного в речи предтермина, используемого в качестве термина [Гринев-Гриневич, 2008, c. 43-47]). Вне всякого сомнения, число их в языке нормативно-правовых актов необходимо минимизировать.

\section{Заключение}

Сфера цифровых технологий развивается крайне динамично, давая обширный материал для исследований в области терминогенеза. Сложность ситуации обусловлена тем, что новые технологии и связанные и ними отношения в настоящее время только разрабатываются и многие понятия технологической сферы еще не получили общепризнанных наименований. Однако необходимость правового регулирования соответствующих отношений приводит к переносу множества таких понятий в язык права. В классическом представлении этот перенос предполагает включение наиболее значимых терминов в текст нормативно-правовых актов. Посредником при этом выступает правовая доктрина, на составителей которой традиционно возлагается ответственность за качество законодательных терминов и дефиниций. Однако влияние доктрины на формирование рассматриваемого пласта юридической терминологии незначительно - в силу динамизма отношений, за развитием которых теория просто не успевает, либо в силу существующего отрыва юридической науки от правотворческой практики.

В последние годы система нормативноправовых актов и других официальных документов государственного управления претерпевает серьезные изменения за счет появления массива актов стратегического планирования, статус которых в юридической науке до конца не определен. Как было показано выше, в сфере цифровых технологий именно эти акты создают текстовое пространство, где происходит апробация и отбор специальных терминов, подлежащих впоследствии законодательному закреплению.

\section{ПРИМЕЧАНИЕ}

${ }^{1}$ Исследование выполнено в рамках научного проекта РФФИ № 20-011-00583 А «Эксперимен- 
тальные правовые режимы (regulatory sandboxes): зарубежный опыт и перспективы внедрения в современной России».

The research was funded by Russian Foundation for Basic Research. Grant of the RFBR 20-011-00583 A "Experimental legal regimes (regulatory sandboxes): foreign experience and implementation prospects in modern Russia".

\section{СПИСОК ЛИТЕРАТУРЫ}

Баранов В. М., Власенко Н. А., 2019. Метафоры в праве: методологическая опасность и перспективы // Юридическая наука и практика : Вестник Нижегородской академии МВД России. № 1 (45). С. 11-19. DOI: 10.24411/2078-53562019-10101.

Быстрова А. С., 2017. Жанровые параметры стратегии как документа долгосрочного планирования // Вестник Волгоградского государственного университета. Серия 2, Языкознание. Т. 16, № 3. С. 199-206. DOI: https://doi.org/ 10.15688/jvolsu2.2017.3.20.

Быстрова А. С., 2018. Речевая организация программы развития как документа стратегического планирования // Научный диалог. № 5. С. 19-29.

Вайпан В. А. 2018. Правовое регулирование цифровой экономики // Приложение к журналу «Предпринимательское право». № 1. С. 12-17.

Власенко С. В., 2014. Метафоры в языке права // Вестник Тверского государственного университета. Серия «Филология». № 4. С. 23-30.

Гаврилова И. А., 2019. Термины-метафоры в составе англоязычной юридической терминологии // Вестник Кемеровского государственного университета. № 21 (2). С. 504-512. DOI: 10.21603/2078-8975-2019-21-2-504-512.

Горохова Н. В., 2014. Проблема соотнесения понятий «термин» и «нетермин» в современной лингвистике // Омский научный вестник. № 3 (129). C. 104-107.

ГОСТ Р 54869-2011. Проектный менеджмент. Требования к управлению проектом, 2012. Введ. 2011-12-22. М. : Стандартинформ. 7 с.

ГОСТ Р ИСО 9000-2015. Системы менеджмента качества. Основные положения и словарь, 2015. Введ. 2015-09-28. М. : Стандартинформ. V, 54 с.

Гринев-Гриневич С. В., 2008. Терминоведение. М. : Академия. $304 \mathrm{c}$.

Догадайло Е. Ю., 2019. Стратегическое планирование в Российской Федерации как механизм, определяющий национальные стратегические приоритеты в современных экономических условиях: развитие нормативного регулирования и поиск конституционно-правовых основ // Право и государство: теория и практика. № 2 (170). С. 29-35.

Зубарев Г. П., 2009. Терминоиды: особенности функционирования в терминологической системе языка // Иностранные языки в высшей школе. № 4 (11). С. 113-119.

Косова М. В., 2010. Специальная лексика в документном тексте: аспекты лингвистического анализа // Вестник Волгоградского государственного университета. Серия 2, Языкознание. № 2 (12). С. 7-12.

Косова М. В., 2012. Системность как свойство документного текста // Вестник Волгоградского государственного университета. Серия 2, Языкознание. № 1 (15). С. 7-11.

Лейчик В. М., 2009. Терминоведение: предмет, методы, структура. М. : Либроком. 256 с.

Лотте Д. С., 1982. Вопросы заимствования и упорядочения иноязычных терминов и терминоэлементов. М. : Наука. 149 с.

Лыкова Н. Н., 2016. Метафора в терминологии права (на материале старофранцузских источников) // Вестник Челябинского государственного университета. Филологические науки. Вып. 100, № 4 (386). С. 106-111.

Черданцев А. Ф., 2012. Логико-языковые феномены в юриспруденции. М. : Норма : ИНФРА-М. 320 с.

Assal A., 1994. La métaphorisation terminologique // Terminologie et traduction. Vol. 2. P. 235-242.

Davydova M. L., Makarov V. O., 2020. Experimental Legal Regimes (Regulatory Sandboxes): Theoretical Problems and Implementation Prospects in Modern Russia // Competitive Russia: Foresight Model of Economic and Legal Development in the Digital Age : International Scientific Conference in Memory of Oleg Inshakov (1952-2018). Cham : Springer, pp. 577-584. (Lecture Notes in Networks and Systems ; vol. 110 / ed. by A. Inshakova, E. Inshakova). DOI: https://doi.org/10.1007/9783-030-45913-0_68.

Hallatt W., 2016. Hong Kong Launches Regulatory Sandbox in Wake of Developments in Australia, Malaysia, Singapore, and the UK // Conventus Law. URL: http://www.conventuslaw.com/report/ hong-kong-launches-regulatory-sandbox-inwake-of/ (date of access: 20.12.2019).

Jenik I., Lauer K., 2017. Regulatory Sandboxes and Financial Inclusion // Working Paper. Washington, D.C. : CGAP. URL: https://www.cgap.org/sites/ default/files/Working-Paper-RegulatorySandboxes-Oct-2017.pdf (date of access: 20.12.2019).

Wechsler M., Perlman L., Gurung N., 2018. The State of Regulatory Sandboxes in Developing Countries Columbia Business School. URL: 
https://dfsobservatory.com/publication/stateregulatory-sandboxes-developing-countries (date of access: 20.12.2019).

Zetzsche D., Buckley R., Arner D., Barberis J. N., 2017. Regulating a Revolution: From Regulatory Sandboxes to Smart Regulation // EBI Working Paper Series. No. 11. URL: https://bit.ly/2NiZlav (date of access: 20.12.2019).

\section{ИСТОЧНИКИ}

Bexa - Веха. Глоссарий // Проектная практика. URL: https://pmpractice.ru/knowledgebase/gloss/detail/ 518.php (дата обращения: 15.01.2020).

Глоссарий - Глоссарий по управлению проектами. Высшая школа управления проектами. URL: https://pm.hse.ru/words (дата обращения: 15.01.2020).

Паспорт нацирограммы - Паспорт нацпрограммы «Цифровая экономика» и шести федеральных проектов. Экспресс-анализ TAdviser // TAdviser: Государство. Бизнес. ИТ. URL: http://www.tadviser.ru/index.php/ $\% \mathrm{D} 0 \% \mathrm{~A} 1 \% \mathrm{D} 1 \% 82 \% \mathrm{D} 0 \% \mathrm{~B} 0 \% \mathrm{D} 1 \% 82 \% \mathrm{D} 1 \%$ 8C\%D1\%8F:\%D0\%9D\%D0\%B0\%D1\%86\% D0\%B8\%D0\%BE\%D0\%BD $\%$ D0\%B0\%D0\% BB $\%$ D $1 \% 8 \mathrm{C} \% \mathrm{D} 0 \% \mathrm{BD} \% \mathrm{D} 0 \% \mathrm{~B} 0 \% \mathrm{D} 1 \%$ $8 \mathrm{~F} \% \mathrm{D} 0 \% \mathrm{BF} \% \mathrm{D} 1 \% 80 \% \mathrm{D} 0 \% \mathrm{BE} \% \mathrm{D} 0 \% \mathrm{~B} 3 \%$ D $1 \% 80 \% \mathrm{D} 0 \% \mathrm{~B} 0 \% \mathrm{D} 0 \% \mathrm{BC} \% \mathrm{D} 0 \% \mathrm{BC} \% \mathrm{D} 0 \%$ B0 \%D0\%A6\%D0\%B8\%D1\%84\%D1\%80\% D $0 \%$ BE $\%$ D $0 \%$ B $2 \%$ D 0\%B $0 \%$ D $1 \% 8 \mathrm{~F}$ $\% \mathrm{D} 1 \% 8 \mathrm{D} \% \mathrm{D} 0 \% \mathrm{BA} \% \mathrm{D} 0 \% \mathrm{BE} \% \mathrm{D} 0 \% \mathrm{BD} \%$ D0\%BE\%D0\%BC\%D0\%B $\%$ D $0 \%$ BA $\%$ D0\%B0_\%D0\%A0\%D0\%BE\%D1\%81\% D $1 \% 81 \%$ D0\%B $8 \%$ D0\%B9\%D $1 \% 81 \%$ D0\%BA\%D0\%BE\%D0\%B9 \%D0\%A4\% D $0 \%$ B $5 \%$ D $0 \%$ B $4 \%$ D $0 \%$ B $5 \%$ D $1 \% 80 \%$ D 0\%B $0 \%$ D 1\%86\%D0\%B $8 \%$ D0\%B $8 \#$. D0.9D.D0.B5.D1.81.D0.BE.D0.B2.D0.BF.D0. B0.D0.B4.D0.B5.D0.BD.D0.B8.D0.B5_.D1. 86.D0.B8.D1.84.D1.80_D0.B2_.C2.AB.D0. A6.D0.B8.D1.84.D1.80.D0.BE.D0.B2.D0.BE. D0.B9 .D1.8D.D0.BA.D0.BE.D0.BD.D0.BE.D0.BC. D0.B8.D0.BA.D0.B5.C2.BB (дата обращения: 15.01.2020).

\section{REFERENCES}

Baranov V.M., Vlasenko N.A., 2019. Metafory v prave: metodologicheskaya opasnost i perspektivy [Metaphors in Law: Methodological Danger and Prospects]. Yuridicheskaya nauka i praktika: Vestnik Nizhegorodskoy akademii MVD Rossii [Legal Science and Practice: Journal of Nizhny
Novgorod Academy of the Ministry of Internal Affairs of Russia], no. 1 (45), pp. 11-19. DOI: 10.24411/2078-5356-2019-10101.

Bystrova A.S., 2017. Zhanrovye parametry strategii kak dokumenta dolgosrochnogo planirovaniya [Genre Parameters of Strategy as a Document of LongTerm Planning]. Vestnik Volgogradskogo gosudarstvennogo universiteta. Seriya 2, Yazykoznanie [Science Journal of Volgograd State University. Linguistics], vol. 16, no. 3, pp. 199-206. DOI: https://doi.org/10.15688/jvolsu2.2017.3.20.

Bystrova A.S., 2018. Rechevaya organizatsiya programmy razvitiya kak dokumenta strategicheskogo planirovaniya [Speech Organization of Development Program as Strategic Planning Document]. Nauchnyy dialog [Scientific Dialogue], no. 5, pp. 19-29.

Vajpan V.A., 2018. Pravovoe regulirovanie tsifrovoy ekonomiki [Legal Regulation ofDigital Economy]. Prilozhenie $k$ zhurnalu Predprinimatelskoe pravo [Appendix to the Journal of Entrepreneurship Law], no. 1, pp. 12-17.

Vlasenko S.V., 2014. Metafory v yazyke prava [Metaphors in Legal Language]. Vestnik Tverskogo gosudarstvennogo universiteta. Seriya "Filologiya", no. 4, pp. 23-30.

Gavrilova I.A., 2019. Terminy-metafory v sostave angloyazychnoy yuridicheskoy terminologii [Metaphorical Terms as Part of English Legal Terminology]. Vestnik Kemerovskogo gosudarstvennogo universiteta [Bulletin of Kemerovo State University], no. 21 (2), pp. 504512. DOI: 10.21603/2078-8975-2019-21-2-504-512.

Gorokhova N.V., 2014. Problema sootneseniya ponyatiy «termin» $\mathrm{i}$ «netermin» v sovremennoy lingvistike [The Problem of Notions "Term" and "Word" in Modern Linguistics]. Omskiy nauchnyy vestnik [Omsk Scientific Bulletin], no. 3 (129), pp. 104-107.

GOST $R$ 54869-2011. Proektnyy menedzhment. Trebovaniya $k$ upravleniyu proektom, 2012 [National Standard of the Russian Federation. Project Management. Project Management Requirements]. Introduced December 22, 2011. Moscow, Standartinform. 7 p.

GOST R ISO 9000-2015. Sistemy menedzhmenta kachestva. Osnovnye polozheniya i slovar, 2015 [National Standard of the Russian Federation. Quality Management Systems. Fundamentals and Vocabulary]. Introduced September 28, 2015. Moscow, Standartinform. V, $54 \mathrm{p}$.

Grinev-Grinevich S.V., 2008. Terminovedenie [Terminology Studies]. Moscow, Akademiya Publ. $304 \mathrm{p}$.

Dogadaylo E.Ju., 2019. Strategicheskoe planirovanie v Rossiyskoy Federatsii kak mekhanizm, 
opredelyayushchiy natsionalnye strategicheskie prioritety $\mathrm{v}$ sovremennykh ekonomicheskikh usloviyakh: razvitie normativnogo regulirovaniya i poisk konstitutsionno-pravovykh osnov [Strategic Planning in the Russian Federation as the Mechanism by Which National Strategic Priorities in the Current Economic Environment: Regulatory and Development Search Constitutional and Legal Framework]. Pravo $i$ gosudarstvo: teoriya i praktika [Law and State: The Theory and Practice], no. 2 (170), pp. 29-35.

Zubarev G.P., 2009. Terminoidy: osobennosti funktsionirovaniya $\mathrm{v}$ terminologicheskoy sisteme yazyka [Terminoids: The Peculiarities of Their Usage and Functions in the Terminological System of Language]. Inostrannye yazyki v vysshey shkole [Foreign languages in Tertiary Education], no. 4 (11), pp. 113-119.

Kosova M.V., 2010. Spetsialnaya leksika v dokumentnom tekste: aspekty lingvisticheskogo analiza [Special Vocabulary in Document Text: Aspects of Linguistic Analysis]. Vestnik Volgogradskogo gosudarstvennogo universiteta. Seriya 2, Yazykoznanie [Science Journal of Volgograd State University. Linguistics], no. 2(12), pp. 7-12.

Kosova M.V., 2012. Sistemnost kak svoystvo dokumentnogo teksta [Systematics Features of a Document Text]. Vestnik Volgogradskogo gosudarstvennogo universiteta. Seriya 2, Yazykoznanie [Science Journal of Volgograd State University. Linguistics], no. 1 (15), pp. 7-11.

Leychik V.M., 2009. Terminovedenie: predmet, metody, struktura [Terminology Studies: Subject, Methods, Structure]. Moscow, Librokom Publ. $256 \mathrm{p}$.

Lotte D.S., 1982. Voprosy zaimstvovaniya $i$ uporyadocheniya inoyazychnykh terminov $i$ terminoelementov [Borrowing and Streamlining Issues of Foreign Terms and Term Elements]. Moscow, Nauka Publ. 149 p.

Lykova N.N., 2016. Metafora v terminologii prava (na materiale starofrantsuzskikh istochnikov) [Metaphor in the Terminology of Law (Based on Material From Old French Sources)]. Vestnik Chelyabinskogo gosudarstvennogo universiteta. Filologicheskie nauki [Bulletin of Chelyabinsk State University. Philology Sciences], iss. 100, no. 4 (386), pp. 106-111.

Cherdantsev A.F., 2012. Logiko-yazykovye fenomeny $v$ yurisprudentsii [Logical and Linguistic Phenomena in Jurisprudence]. Moscow, Norma Publ., INFRA-M Publ. 320 p.

Assal A., 1994. La métaphorisation terminologique. Terminologie et traduction, vol. 2, pp. 235-242.
Davydova M.L., Makarov V.O., 2020. Experimental Legal Regimes (Regulatory Sandboxes): Theoretical Problems and Implementation Prospects in Modern Russia. Competitive Russia: Foresight Model of Economic and Legal Development in the Digital Age: International Scientific Conference in Memory of Oleg Inshakov (1952-2018). Cham, Springer, pp. 577-584. (Inshakova A., Inshakova E., eds. Lecture Notes in Networks and Systems; vol. 110). DOI: https://doi.org/10.1007/978-3-03045913-0_68.

Hallatt W., 2016. Hong Kong Launches Regulatory Sandbox in Wake of Developments in Australia, Malaysia, Singapore, and the UK. Conventus Law. URL: http://www.conventuslaw.com/report/ hong-kong-launches-regulatory-sandbox-inwake-of/ (accessed 20 December 2019).

Jenik I., Lauer K., 2017. Regulatory Sandboxes and Financial Inclusion. Working Paper. Washington, D.C., CGAP. URL: https://www. cgap.org/sites/default/files/Working- PaperRegulatory-Sandboxes-Oct-2017.pdf(accessed 20 December 2019).

Wechsler M., Perlman L., Gurung N., 2018. The State of Regulatory Sandboxes in Developing Countries Columbia Business School. URL: https://dfsobservatory.com/publication/stateregulatory-sandboxes-developing-countries (accessed 20 December 2019).

Zetzsche D., Buckley R., Arner D., Barberis J.N., 2017. Regulating a Revolution: From Regulatory Sandboxes to Smart Regulation. EBI Working Paper Series, no. 11. URL: https://bit.ly/2NiZlav (accessed 20 December 2019).

\section{SOURCES}

Vekha. Glossariy [Milestone. Glossary]. Proektnaya praktika [Design Practice]. URL: https:// pmpractice.ru/knowledgebase/gloss/detail/ 518.php (accessed 15 January 2020).

Glossariy po upravleniyu proektami. Vysshaya shkola upravleniya proektami [Project Management Glossary. High School of Project Management]. URL: https://pm.hse.ru/words (accessed 15 January 2020).

Pasport natsprogrammy «Tsifrovaya ekonomika» i shesti federalnykh proektov. Ekspress-analiz TAdviser [Passport of the National Program "Digital Economy" and Six Federal Projects. TAdviser Express Analysis]. TAdviser: Gosudarstvo. Biznes. IT [TAdviser: State. Business. IT]. URL: http:// w w w . t a d vi s e r. r u / i n d e x . p h p / $\%$ D0\%A1\%D1\%82\%D0\%B0\%D1\%82\%D1\% 
М.Л. Давыдова. Формирование и нормализация юридической терминологии

8C\%D1\%8F:\%D0\%9D\%D0\%B0\%D1\%86\%

D0 $\%$ B $8 \%$ D0 $\%$ BE $\%$ D0 $\%$ BD $\%$ D0 $\%$ B $\%$ D0 $\%$

BB $\%$ D $1 \% 8 \mathrm{C} \% \mathrm{D} 0 \% \mathrm{BD} \% \mathrm{D} 0 \% \mathrm{~B} 0 \% \mathrm{D} 1 \%$

$8 \mathrm{~F} \% \mathrm{D} 0 \% \mathrm{BF} \% \mathrm{D} 1 \% 80 \% \mathrm{D} 0 \% \mathrm{BE} \% \mathrm{D} 0 \% \mathrm{~B} 3 \%$

D1\%80\%D0\%B0\%D0\%BC\%D0\%BC\% D0\%

B0_\%D0\%A6\%D0\%B8\%D1\%84\%D1\%80\%

$\mathrm{D} 0 \% \mathrm{BE} \% \mathrm{D} 0 \% \mathrm{~B} 2 \% \mathrm{D} 0 \% \mathrm{~B} 0 \% \mathrm{D} 1 \% 8 \mathrm{~F}$

$\% \mathrm{D} 1 \% 8 \mathrm{D} \% \mathrm{D} 0 \% \mathrm{BA} \% \mathrm{D} 0 \% \mathrm{BE} \% \mathrm{D} 0 \% \mathrm{BD} \%$

D $0 \% \mathrm{BE} \% \mathrm{D} 0 \% \mathrm{BC} \% \mathrm{D} 0 \% \mathrm{~B} 8 \% \mathrm{D} 0 \% \mathrm{BA} \%$

D0\%B0_\%D0\%A0\%D0\%BE\%D1\%81\%
D $1 \% 81 \%$ D0\%B 8\%D0\%B9\%D $1 \% 81 \%$ D0\%BA\%D0\%BE\%D0\%B9_\%D0\%A4\% D $0 \%$ B $5 \%$ D $0 \%$ B 4\%D $0 \%$ B $5 \%$ D $1 \% 80 \%$ D $0 \%$ B $0 \%$ D $1 \% 86 \%$ D0\%B $8 \%$ D $0 \%$ B $8 \#$. D0.9D.D0.B5.D1.81.D0.BE.D0.B2.D0.BF.D0. B0.D0.B4.D0.B5.D0.BD.D0.B8.D0.B5_.D1. 86.D0.B8.D1.84.D1.80_.D0.B2_.C2.AB.D0. A6.D0.B8.D1.84.D1.80.D0.BE.D0.B2.D0.BE. D0.B9 .D1.8D.D0.BA.D0.BE.D0.BD.D0.BE.D0.BC.D0. B8.D0.BA.D0.B5.C2.BB(accessed 15 January2020).

\section{Information About the Author}

Marina L. Davydova, Doctor of Sciences (Jurisprudence), Professor, Head of the Department of Constitutional and Municipal Law, Volgograd State University, Prosp. Universitetsky, 100, 400062 Volgograd, Russia, davidovavlg@gmail.com, davidovaml@volsu.ru, https://orcid.org/0000-0001-8392-9592

\section{Информация об авторе}

Марина Леонидовна Давыдова, доктор юридических наук, профессор, заведующая кафедрой конституционного и муниципального права, Волгоградский государственный университет, просп. Университетский, 100, 400062 г. Волгоград, Россия, davidovavlg@gmail.com, davidovaml@volsu.ru, https://orcid.org/0000-0001-8392-9592 